\title{
Cenários, tendências e desafios na formação de professores de Ciências Sociais no Brasil'
}

Amurabi Oliveira ${ }^{2}$

\section{Resumo}

A Lei $n^{\circ}$ I1.684/2008, que reintroduziu a Sociologia na Educação Básica, trouxe novos desafios não apenas para as escolas, mas também para as Instituições de Ensino Superior (IES), o que tem como efeito mais imediato o incremento no número de cursos de formação de professores em Ciências Sociais/Sociologia. Neste artigo, busca-se apresentar o cenário atual dos cursos de formação de professores no Brasil em termos quantitativos, indicando sua distribuição pelo país, bem como a expansão de tais cursos ocorrida com a reintrodução da Sociologia no Ensino Médio. Posteriormente, busca-se realizar uma análise dos dados apresentados, indicando as tendências que podem ser percebidas, e também quais os desafios que se colocam para a formação de professores de Ciências Sociais/Sociologia nesse novo cenário.

Palavras-chave: Ensino de Sociologia. Formação de professores em Ciências Sociais. Ensino Superior. Sociologia da Educação.

\section{Introdução}

$\mathrm{O}$ processo de reintroduçáo da Sociologia de forma obrigatória em todas as séries do Ensino Médio no Brasil, o que se deu a partir do Parecer CNE/ CEB no 38/2006 e da Lei no 11.684/2008, é algo cujos impactos ultrapassam a realidade da Educaçấo Básica, uma vez que a longa ausência desta ciência no currículo escolar resultou em um redirecionamento dos cursos de Ciências

I Uma versão preliminar desse trabalho foi apresentada durante o I Encontro de Sociologia e Educação: desafios para a formação de professores para o Ensino de Sociologia, cujas atividades ocorreram entre os dias 20 e 22 de maio na Universidade Federal do Maranhão (UFMA).

2 Dados do autor?Doutor em Sociologia pela Universidade Federal de Pernambuco (UFPE), Professor da Universidade Federal de Santa Catarina (UFSC).Pesquisador do CNPq.E-mail: amurabi_cs@hotmail.com 
Sociais durante um longo período, o que ocorreu de forma concomitante com a solidificação do campo da pesquisa no Brasil com o advento da pós-graduação no modelo próximo ao que conhecemos com a Reforma Universitária de 1968, e da mesma maneira a volta da Sociologia à escola tem implicado uma elaboração de novos olhares sobre os cursos de formação de professores de Sociologia.

Apesar da expansão do Ensino Superior brasileiro ser algo que começa a ocorrer de forma mais evidente ainda nos anos de 1970, acelerando-se nos anos de 1990 (NEVES; FACHINETTO; RAIZER, 2007; MARTINS, 2009) - o que incluiu, também, as Ciências Sociais que passam a contar com um número crescente de cursos de graduação nesse período (LIEDKE FILHO, 2005) -, e analisando os dados referentes aos atuais cursos existentes no Brasil nessa área, podemos verificar que a expansão das licenciaturas em Ciências Sociais/Sociologia ${ }^{3}$ é algo que possui uma aceleração recente. Desse modo, poderíamos afirmar que houve nessa área uma "expansão tardia", se compararmos com o cenário mais amplo do Ensino Superior no país, impulsionada pelo retorno da Sociologia ao currículo escolar.

O que denomino aqui de "expansão tardia" tem contado com uma presença crescente do privado de ensino, o que segue uma tendência mais ampla observada na expansão do Ensino Superior brasileiro, o que também é um elemento relativamente "novo" nos cursos de Ciências Sociais. Chama a atenção, ainda, a crescente pluralidade institucional na oferta, havendo uma presença crescente de cursos náo universitários, bem como de alguns realizados na modalidade Educação a Distância (EAD).

A pesar de ter havido um incremento significativo nas pesquisas relacionadas com o Ensino de Sociologia nos últimos anos, como podemos observar a partir do aumento quantitativo de teses e dissertaçóes dedicadas ao tema (HANDFAS, MAÇAIRA, 2014), ainda não tem ocorrido uma análise mais detalhada sobre o fenômeno da expansáo dos cursos de formação de professores de Sociologia nos últimos anos, de tal modo que se almeja, com este artigo, contribuir para essa discussão, dentro dos limites de seu escopo.

3 A denominação mais recorrente de tais cursos ainda é Ciências Sociais. Em todo o caso, como a disciplina que existe no currículo escolar é a Sociologia, irei me referir, em alguns momentos, ao longo desse artigo como cursos de formação de professores de Sociologia, já que tanto as licenciaturas em Ciências Sociais quanto as em Sociologia habilitam seus egressos para lecionarem essa disciplina no Ensino Médio. 
Neste trabalho, proponho-me a analisar esse processo que ainda está em curso no Brasil, o que será realizado considerando os dados disponíveis na plataforma do Sistema e-MEC ${ }^{4}$, buscando compreender os significados dessa expansão quantitativa em nível nacional, problematizando, a partir daí, os desafios que estáo sendo postos neste cenário. Trata-se da análise de um cenário em transformaçáo, que é realizado a partir do levantamento inicial de dados com relação aos cursos existentes ${ }^{5}$.

Apesar da relevância que a EAD passou a ganhar nos últimos anos, neste texto meu recorte se circunscreve aos cursos presenciais, uma vez que compreendo que há uma maior heterogeneidade nos cursos nas modalidades semipresencial e a distância, que mereceria uma análise mais detalhada que pudesse captar suas questóes idiossincráticas especialmente no campo das Ciências Sociais (OLIVEIRA; BRUM, 2014). Ademais, como os cursos mais antigos no país funcionam exclusivamente na modalidade presencial, observar a expansão nesse tipo de formação nos possibilita realizar um exercício comparativo mais claro entre o período que antecede a reintrodução da Sociologia na escola e aquele que o sucede.

Devo frisar aqui, embora que não haja a oportunidade de aprofundar esse ponto, que a expansão quantitativa de cursos de Ciências Sociais na modalidade EAD, concentrada quase exclusivamente no setor privado, pode contribuir para o debate acadêmico sobre o Ensino de Sociologia, na medida em que traz novos elementos que complexificam o cenário já existente. Sem embargo, deve-se considerar que há uma necessidade de avaliar de modo qualitativo tais cursos, o que somente poderá ser realizado em médio prazo. Uma questáo que seria pertinente de se colocar é a seguinte: "em que medida se mostra válida a criação de tais cursos como uma saída emergencial para a demanda existente em termos formativos dos professores de Sociologia, uma vez que a maior parte absoluta dos professores dessa área que atuam na Educação Básica não

4 Disponivel em: <http://emec.mec.gou.br/>.

5 Há um limite posto na ferramenta utilizada que deve ser destacado, pois a plataforma e-MEC, apesar de ser a principal fonte de dados com relação ao número de cursos superiores existentes no Brasil, indica de forma indiscriminada cursos autorizados, mas ainda que não iniciaram suas atividades, cursos que, apesar de existentes, estão encerrando suas turmas não abrindo novas.. E os cursos que estão funcionando e recebendo novas turmas referem-se aos cursos autorizados para funcionar atualmente, incluindo os que irão iniciar suas atividades e aqueles que devem encerrar suas turmas em breve, ainda que esse grupo constitua uma minoria pelo que se pôde verificar. 
possuem licenciatura em Ciências Sociais?”. Trata-se de uma tendência mais ampla e geral observada no Ensino Superior brasileiro como um todo, e que tem desafiado o modo de encararmos formação inicial docente.

\section{Breve contextualização dos Cursos de Ciências Sociais}

Como é bem sabido, o processo de introdução da Sociologia na Educação Básica antecede a criação dos cursos de Ciências Sociais, de tal modo que os primeiros professores dessa disciplina escolar eram, em sua maioria, autodidatas nessa área de conhecimento (MEUCCI, 2011). Ainda no final do século XIX houve experiências pontuais de introdução dessa ciência na escola, como ocorreu no Atheneu Sergipense (OLIVEIRA, 2013b); porém, foi com a Reforma Rocha Vaz (1925) e Francisco Campos (1931) que a Sociologia se consolidou no currículo escolar.

Foi na década de 1930 que surgiram os primeiros cursos de Ciências Sociais no Brasil: primeiramente na Escola Livre de Sociologia e Política de São Paulo (ELSP) em 1933; logo em seguida, na Universidade de São Paulo (USP) em 1934 e na Universidade do Distrito Federal (UFD) em 1935. $\mathrm{O}$ curso criado na Escola Livre tinha um perfil voltado claramente para a formação de um quadro técnico, ao passo que aqueles existentes na USP e na UDF voltam-se, embora náo de forma exclusiva, para a formaçáo de professores, não à toa, Miceli (1989) aponta que as primeiras turmas do curso de Ciências Sociais da USP eram compostas principalmente por estudantes arregimentados entre os professores, majoritariamente professoras, do ensino primário e secundário, destacando-se além da forte presença de mulheres e de filhos de migrantes nesse corpo estudantil, o que destoava do perfil corriqueiro nos cursos mais tradicionais nesse mesmo período.

Há que se enfatizar que a tradição intelectual que se instaurou naquele momento teve um peso significativo sobre os desdobramentos ulteriores, o que pode ser observado no perfil dos cursos de Ciências Sociais, pois foi a partir

6 É necessário esclarecer que o curso de Ciências Sociais da UDF funcionou entre os anos de 1935 a 1939. período de atividade desta instituição que fora criada por Anísio Teixeira; após esse período seu patrimônio bem como seus alunos foram incorporados à Faculdade Nacional de Filosofia da Universidade do Brasil, esta viria a dar origem à Universidade Federal do Rio de Janeiro. Embora se possa falar que houve uma simples transmutação de uma instituição em outra, em todo o caso, o curso passou a ser abrigado pela UFRJ, sendo ofertado de forma regular nesta instituição desde 1939. 
desse momento que se constituiu no Brasil uma determinada organização curricular que "perdura" até o momento, visto que o curso de Ciências Sociais tornou-se sinônimo de uma articulação entre Antropologia, Ciência Política e Sociologia. Pode-se notar uma leve preponderância da Sociologia por vezes, o que ocorreu ante uma tênue divisão disciplinar existente naquele momento (MICELI, 1989). Torna-se hegemônico, portanto, esse modo de pensar tais cursos, apesar de se ter perdido alguns outros diálogos fundamentais com outras áreas de conhecimento quando se optou por privilegiar esse arranjo (MAGGIE, 2006).

Liedke Filho (2005) aponta para uma crescente institucionalização das Ciências Sociais no Brasil por meio da criação de novos cursos de graduação, especialmente no período compreendido entre 1954 e 1976. Essa expansáo acentuada ocorreu em um momento em que a Sociologia não se encontra nos currículos escolares de forma obrigatória através de uma disciplina escolar, considerando sua retirada, ainda em 1942, por meio da Reforma Capanema ${ }^{7}$; dessa forma, pode-se aventar a hipótese de que não há um automatismo entre a expansão do número de cursos de Ciências Sociais e a presença da Sociologia no currículo escolar, ou seja, quando esses dois fenômenos ocorrem de forma concomitante, isso deve ser interpretado considerando o perfil dos cursos que surgem, as dinâmicas no currículo escolar, bem como o contexto do Ensino Superior como um todo.

Não se pode olvidar, nesse contexto, duas questóes: $1^{\text {a)}}$ nesse período, houve um salto significativo em termos numéricos em todos os cursos superiores no país, especialmente a partir da Reforma Universitária de 1968; $2^{a}$ ) ainda que considerando a ausência da Sociologia no currículo escolar, a licenciatura em Ciências Sociais era compreendida como um curso que habilitava seu egresso para o ensino de diversas disciplinas escolares, como História e Geografia, e posteriormente Organização Social e Política do Brasil (OSPB) e Educaçáo Moral e Cívica.

7 Para evitar mal-entendidos, é válido frisar que, no conjunto de reformas no ensino realizado pelo então Ministro da Educação Gustavo Capanema (1900-1985), ocorreu a supressão dos chamados cursos complementares nos quais a Sociologia estava alocada, de modo que sua retirada do curriculo não representou uma ação pontual direcionada a esta disciplina, mas sim um resultado de uma ação mais ampla. Acerca desse acontecimento, Moraes (20I I, p. 364) levanta a seguinte hipótese: "A esta altura, 1942, as Ciências Sociais, em geral, e a Sociologia, em particular, ainda não tinham ganhado legitimidade para figurar como uma ciência e não se assumiam como uma possivel alternativa a essa Literatura, de modo que não cumpriam, de certa forma, os quesitos necessários para se enquadrarem no currículo do clássico ou do científico". 
Obviamente, deve-se considerar que as trajetórias dos diversos cursos de graduação não são lineares, havendo alguns que são fechados nesse interstício por diversos motivos. Por isso, neste texto, vou me ater àqueles que atualmente se encontram em funcionamento; e, dentre estes, nesse momento, destacarei aqueles que surgiram no período anterior à reintrodução da Sociologia no Currículo Escolar. Outra questáo relevante refere-se à heterogeneidade regional, uma vez que cada regiáo do país possui um cenário substancialmente distinto quanto ao Ensino Superior, bem como ao Ensino de Sociologia na Educação Básica.

\section{Os cursos de formação de professores de Sociologia antes da Lei $n^{\circ} 11.684 / 2008$}

Como já foram lançados alguns indicativos, buscarei aprofundar alguns pontos que apenas foram rapidamente tocados no tópico anterior. Irei expor, ao leitor, quais os cursos de licenciatura em Ciências Sociais/Sociologia, dentre os que ainda estão em funcionamento, existiam antes da reintrodução da disciplina em 2008, analisando o perfil recorrente a estes, principalmente no que se refere à distribuição geográfica e ao tipo de Instituição de Ensino Superior (IES) na qual estão inseridos. Para tanto, precisarei percorrer esse cenário nacional a partir dos contextos mais regionais, buscando, com isso, captar melhor as singularidades existentes.

Como os cursos de Ciências Sociais surgiram no Brasil primeiramente na região Sudeste, considero pertinente iniciar a exposição dos dados pelos cursos existentes nesta região. Além disso, tendo em vista que esta é a que concentra o maior número de cursos, creio que é válido analisar o caso de cada estado.

São Paulo apresenta-se como o estado com o maior número de cursos de Ciências Sociais/Sociologia, sendo estes, via de regra, bastante antigos. Há, neste estado, dez cursos de formação de professores de Sociologia, e que já existiam antes da obrigatoriedade dessa disciplina no Ensino Médio em nível nacional, estando tais cursos alocados junto às seguintes instituiçóes: Universidade de São Paulo (1934), Pontifícia Universidade Católica de Campinas (1942), Universidade Estadual Paulista (1963) nos campi de Marília e Araraquara, Centro Universitário Fundação Santo André (1966), Faculdade de Filosofia, Ciências e Letras de Itapetininga (1968), Centro Universitário 
Sant'Anna (1970), Universidade Estadual de Campinas (1970), Instituto Superior de Educação Ceres (2004), Universidade Federal de São Paulo (2007).

No Rio de Janeiro, há seis cursos que já ofertavam a licenciatura antes de 2008: Universidade Federal do Rio de Janeiro (1939), Universidade do Estado do Rio de Janeiro (1941), Pontifícia Universidade Católica do Rio de Janeiro (1941), Universidade Federal Fluminense (1964) no campi Gragoatá em Niteroi ${ }^{8}$, Faculdades Integradas Campo Grandenses (1966), Universidade Cândido Mendes (2002).

Em Minas Gerais, são seis cursos de formação de professores em funcionamento que iniciaram suas atividades até 2007: Universidade Federal de Minas Gerais (1941), Universidade Federal de Juiz de Fora (1948), Universidade Estadual de Montes Claros (1968), Universidade Vale do Rio Doce (1968), Universidade Federal de Uberlândia (1997), Centro de Ensino Superior de Uberaba (2002).

Já no Espírito Santo, o único curso presencial existente de Ciências Sociais é o da Universidade Federal do Espírito Santo (1991), que oferta tanto o bacharelado quanto a licenciatura.

Dos 23 cursos existentes na regiáo sudeste até o ano de 2007, podemos observar que sua maioria estava concentrada em instituiçóes universitárias: 17 (73\%), com uma leve preponderância de IES públicas: 13 (56\%), ainda que se deva reconhecer que, dentro da regiáo, há grandes disparidades nesse quesito, havendo, ainda, um número significativo de cursos que surgem entre as décadas de 1960 e 1970: oito (34\%). Chama a atenção, ainda, que nos anos de 1980 e 1990 nenhuma licenciatura de Ciências Sociais foi criada em São Paulo ou no Rio de Janeiro, e apenas uma em Minas Gerais (UFU) e a única do Espírito Santo, o que contrasta com a rápida expansão do Ensino Superior brasileiro especialmente nos anos de 1990.

Na regiáo Sul do Brasil, até 2007, havia: quatro cursos no Paraná junto às seguintes instituiçóes: Universidade Federal do Paraná (1940), Universidade Estadual de Londrina (1973), Universidade Estadual do Oeste do Paraná (1998), e na Universidade Estadual de Maringá (2000); sete cursos no Rio

8 A plataforma e-MEC indicou com relação a este curso "Suspensão de Ingresso e Suspensão de Autonomia Despacho no 191/2012 e Despacho no 192/2012 - Nota Técnica no 933/2012 e Nota Técnica no 934/20 I2". 
Grande do Sul nas seguintes instituiçóes: Pontifícia Universidade Católica do Rio Grande do Sul (1940), Universidade Federal do Rio Grande do Sul (1959), Universidade do Vale dos Sinos (1958), Universidade Regional da Campanha em Bagé no ano de 1965 e em Caçapava do Sul em 1997; na Universidade Federal de Pelotas (1996), e na Universidade de Santa Cruz do Sul (2003); e três em Santa Catarina, assim distribuídos institucionalmente: Universidade Federal de Santa Catarina (1972), Universidade Regional de Blumenau (1987), e Universidade do Contestado (2003).

Dos 14 cursos existentes até entâo, todos estavam alocados em instituiçôes universitárias (100\%), sete em instituiçôes privadas (50\%); porém, diferentemente da regiáo Sudeste, houve a criação de alguns cursos nos anos de 1980 e 1990 no Sul do Brasil. Quatro destes (28\%) surgiram nesse período, o que pode indicar um reflexo do processo paulatino de reintrodução da Sociologia no currículo escolar, que ocorre nos estados dessa regiáo de forma mais enfática a partir dos anos de 1990 por meio das legislaçóes estaduais.

Havia, até 2007, 14 cursos de Ciências Sociais junto às seguintes instituições no Nordeste: Universidade Federal de Alagoas (1993), Universidade Federal da Bahia (1941), Universidade Federal do Ceará (1968), Universidade Estadual do Ceará (1989), Universidade Estadual do Vale do Acaraú (1997), Universidade Regional do Cariri (2006), Universidade Federal do Maranhão (1986), Universidade Estadual do Maranhão (2006), Universidade Federal de Campina Grande em 1962 no campi Campina Grande, Universidade Federal de Pernambuco (2000), Universidade Federal do Piauí (1984), Universidade Estadual do Rio Grande do Norte (1967), Universidade Federal do Rio Grande do Norte (1974), Universidade Federal de Sergipe (1991).

Todos os cursos nessa região encontram-se em instituiçóes universitárias públicas, majoritariamente em IES federais, com exceção dos três cursos existentes no Ceará e um no Rio Grande do Norte. Seis desses cursos (42\%) surgiram entre as décadas de 1980 e 1990, e três nos anos 2000 (21\%), o que indica que são cursos predominantemente jovens. Ademais, na década de 1970 nenhuma licenciatura na área foi criada, sendo importante ressaltar que alguns cursos, apesar de antigos, somente passaram a ofertar a habilitação da licenciatura posteriormente, como é o caso da UFPE, cujo curso de Ciências Sociais data da década de 1950, porém a licenciatura surgiu apenas meio século depois. E isso que pode ser explicado, em parte, devido ao fato de que, 
quando o curso foi criado, a Sociologia já não era mais uma disciplina obrigatória no currículo escolar.

Na regiáo Norte, encontram-se cursos mais jovens, apenas o da Universidade Federal do Pará no campi de Belém é anterior à década de 1980, tendo sido criado em 1954, os demais cursos surgem junto às seguintes instituiçóes: Faculdade Barão do Rio Branco (2002) no Acre; Universidade Federal do Amazonas (1987) e Universidade Nilton Lins (2005) no Amazonas; Universidade Federal do Amapá - em 1997 em Macapá e em 2004 em Laranjal do Jair, e Faculdade de Macapá (2003) no Amapá; Universidade da Amazônia (1980); Universidade Federal do Sul e Sudeste do Pará - em 1994 em Marabá e em 2004 em Rondon do Pará9, no Pará; Universidade Federal de Rondônia (2005), em Rondônia; Universidade Estadual de Roraima (2007) em Roraima; Universidade Federal do Tocantins (2007) no Tocantins.

Havia, nessa regiáo, 13 cursos presenciais de formação de professores de Sociologia até 2007, nove desses cursos (69\%) alocados em instituiçôes públicas, principalmente instituiçóes federais. Entretanto, no Estado no Acre não havia até aquele período nenhum curso público de formação docente nessa área. Chama a atenção o fato de que a maior parte absoluta de tais cursos são bastante recentes, tendo sido criados oito deles (61\%) ainda nos anos 2000, o que pode refletir, também, o processo paulatino de reintrodução da Sociologia nos currículos escolares, dois destes são criados no ano posterior ao parecer do $\mathrm{CNE}$ que visava à reintrodução da Sociologia e da Filosofia na escola. Segue-se, além disso, uma tendência mais geral de uma ampla concentração em instituições universitárias, é o caso de 12 desses cursos (91\%).

No Centro-Oeste, havia apenas duas licenciaturas em Ciências Sociais até 2007: na Universidade Federal de Goiânia, criada em 1962, e na Universidade de Brasília, criada em 1967. Observa-se, portanto, uma oferta bastante restrita por um longo período, concentrada exclusivamente em universidades públicas, que passa a emergir após o deslocamento da capital federal para a regiáo.

Configurou-se, desse modo, um cenário profundamente heterogêneo no que se refere a esses 66 cursos, marcado por uma maior concentração de

9 A UNIFESSPA foi criada em 2013 com o desmembramento de alguns campi da UFPA, de modo que tais cursos, quando surgiram, estavam vinculados à UFPA. 
cursos de formação de professores de Sociologia na Região Sudeste (34\%), seguida do Nordeste (21\%), Sul (21\%), Norte (19\%) e Centro-Oeste (3\%), havendo uma maior penetração das IES privadas nas regióes Sul e Sudeste, 17 das 21 instituiçóes privadas que ofertam o curso encontram-se nessas regióes, portanto $80 \%$ do total, porém, em termos nacionais, podemos afirmar que os cursos existentes até aquele momento estavam concentrados prioritariamente em universidades (89\%), com uma leve preponderância das públicas (68\%). Chama a atenção o fato de que boa parte de tais cursos ofertam, também, a habilitação do bacharelado, até porque normalmente esta antecedeu a criação das licenciaturas.

\section{Os cursos que surgem após a reintrodução da Sociologia no currículo escolar}

Ante aos dados que estáo disponíveis na plataforma e-MEC, pode-se observar um fenômeno interessante envolvendo os cursos de Ensino Superior voltados para a formação de professores de Sociologia: ocorreu uma rápida e contínua expansão, o que foi acompanhado mesmo nos estados nos quais já havia uma legislaçáo local que introduzia a Sociologia. Pode-se perceber, com isso, que a Lei no 11.684/2008 deu maior legitimidade à disciplina Sociologia no currículo escolar, delineando uma maior clareza com relação ao campo de atuação do licenciado, desse modo, ocorreu uma "expansão tardia” de tais cursos, se considerarmos como referência o movimento mais intenso que se deu no Ensino Superior brasileiro principalmente a partir dos anos de 1990.

A região Sudeste que possuía até 2007 o maior número de licenciaturas em Ciências Sociais teve um crescimento mais tímido e heterogêneo, e em Sáo Paulo foram criados apenas mais três cursos de Ciências Sociais: Centro Universitário Claretiano (2008), Universidade Nove de Julho (2009) e Centro Universitário das Faculdades Metropolitanas Unidas (2012) e mais duas licenciaturas em Sociologia: Centro Universitário de Araras “Dr. Edmundo Ulson” (2009) e Centro Universitário Ítalo Brasileiro (2009), o que possivelmente está aquém das demandas postas por sua ampla rede de ensino. Já em Minas, foram criadas licenciaturas em Ciências Sociais junto às seguintes instituiçôes: Instituto Federal de Educação, Ciência e Tecnologia do Triângulo Mineiro (2008), Universidade Federal de Alfenas (2009), Universidade Federal de Viçosa (2009) e Universidade do Estado de Minas Gerais (2012). No 
Rio de Janeiro, tais cursos sugiram junto à Universidade Federal Fluminense no campi de Campos dos Goytacazes (2009), Universidade Federal Rural do Rio de Janeiro (2009), Faculdade São Fidelis (2012) e Universidade Federal do Estado do Rio de Janeiro (2013). Convém destacar que, no Espírito Santo, não houve a criação de novos cursos presenciais nessa área.

Em um curto intervalo, observa-se a criação de mais 13 cursos de formação de professores em Ciências Sociais, um aumento de 56\% no total, com uma leve preponderância das instituiçóes públicas (54\%), ainda que haja uma "heterogeneidade gritante", pois em São Paulo, por exemplo, apenas foram criados cursos junto a IES privadas, já em Minas apenas junto a IES públicas, na mesma proporção também encontramos os cursos que estáo alocados junto a instituiçóes universitárias (56\%), havendo, portando, um avanço da oferta em instituiçóes como Centros Universitários, Faculdades Isoladas e Institutos Federais, estes criados pelo governo federal em 2008.

Na Região Sul, única na qual todos os Estados já contavam com a Sociologia no currículo por meio das legislaçóes estaduais, houve um incremento significativo com o surgimento de quinze novos cursos. No Paraná, a Pontifícia Universidade Católica do Paraná criou, em 2008, a licenciatura em Sociologia, que se transformou, a partir de 2012, em Licenciatura em Ciências Sociais; também foram criadas licenciaturas nessa área na Faculdade Guarapuava (2010), na Faculdade Sagrada Família (2011), no Instituto Federal de Educação, Ciência e Tecnologia do Paraná (2012), e na Faculdade Vicentina (2014). No Rio Grande do Sul, o crescimento foi menos expressivo, tendo surgido três novos cursos, todos no ano de 2010, junto às seguintes instituiçóes: Universidade Federal da Fronteira Sul, Universidade de Caxias do Sul, Universidade Federal de Santa Maria, sendo esta última uma licenciatura em Sociologia. Em Santa Catarina, surgiram as licenciaturas em Ciências Sociais junto à Universidade Federal da Fronteira Sul (2010), Universidade do Contestado na cidade de Mafra (2014), e licenciaturas em Sociologia junto ao Centro Universitário para o Desenvolvimento do Alto Vale do Itajaí (2009), à Universidade Comunitária da Regiáo de Chapecó (2009), à Universidade da Região de Joinville (2009), à Universidade do Oeste de Santa Catarina (2012) e à Universidade do Sul de Santa Catarina (2014). Nessa regiáo, o aumento foi mais significativo (107\%), majoritariamente em instituiçôes universitárias (66\%); portanto, surgem outros tipos de IES ofertando tais cursos, porém 
apenas $26 \%$ dos cursos são em IES públicas, o que demonstra o avanço do setor privado sobre essas licenciaturas.

No Nordeste, foram criados quinze novos cursos, sendo a licenciatura em Ciências Sociais junto às seguintes instituiçóes: Universidade Estadual do Piauí nos campi de Teresina e Parnaíba (2013), Universidade Federal da Paraíba (2009), Universidade Federal de Campina Grande no campi de Sumé (2009), Universidade de Pernambuco (2013), Universidade Federal do Vale do São Francisco (2011), Universidade Estadual de Santa Cruz (2008), Universidade Estadual do Sudoeste da Bahia (2011), Universidade do Estado da Bahia $(2011)^{10}$, Universidade Federal do Recôncavo da Bahia (2014), além das licenciaturas em Ciências Humanas com habilitação em Sociologia na Universidade Federal do Maranhão nos campi de Bacabal, Imperatriz e São Bernardo (2010), e da licenciatura em Sociologia como possibilidade no segundo ciclo junto ao bacharelado em Humanidades da Universidade Federal da Integração Luso-Afro-Brasileira nos campi de Redenção e São Francisco do Conde $(2014)^{11}$.

Houve um aumento de 107\% no número de cursos, mantendo-se todos vinculados a universidades públicas; porém, mesmo aí, encontramos alguns novos elementos, como a existência de licenciaturas interdisciplinares com habilitaçáo em Sociologia, e da licenciatura como parte de um segundo ciclo de um bacharelado interdisciplinar.

$\mathrm{Na}$ região Norte, não houve a criação de nenhum curso presencial de formação de professores de Sociologia, ainda que tenham surgido 18 novos cursos, cada um com vários polos, que funcionam na modalidade EAD.

Já no Centro-Oeste, encontramos o crescimento mais significativo, pois foram criadas novas licenciaturas em Ciências Sociais junto às seguintes IES: Universidade Federal da Grande Dourados (2008), Universidade Estadual de

10 Refiro-me aqui ao curso de licenciatura em Ciências Sociais criado junto ao Departamento de Educação do campi de Salvador da UNEB. Esta universidade criou, em 2009, através do Plano Nacional de Formação de Professores da Educação Básica (PAFOR), cursos de licenciatura presenciais em Sociologia nas cidades de Alagoinhas, Barreiras, Brumado, Itaberaba, Paulo Afonso, Senhor do Bonfim, Teixeira de Freitas; porém, tais cursos apresentam um caráter apenas emergencial.

II Após a realização do chamado primeiro ciclo que corresponde ao Bacharelado em Humanidades, os estudantes podem pleitear a realização do segundo ciclo, e neste são oferecidos o bacharelado em Antropologia, História e Sociologia e as licenciaturas em História, Pedagogia e Sociologia. 
Mato Grosso do Sul nos campi de Amanbaí (2008) e Paranaíba (2009), Universidade Federal do Mato Grosso do Sul (2009), Universidade Federal do Mato Grosso (2010), Instituto Federal de Educação, Ciência e Tecnologia de Goiás nos campi de Anápolis e Formosa (2013) e Universidade Federal de Goiás no campi de Catalão em 2009.

Devido ao diminuto número de cursos existentes até 2007, o crescimento foi de $400 \%$, todo alocado junto a IES públicas, sendo estas majoritariamente universidades $(75 \%)$.

Considerando-se o cenário criado após 2008, temos uma maior concentração de novos cursos na regiáo Nordeste e Sul, seguindo-se do Sudeste, e depois do Centro-Oeste. Se considerarmos o crescimento proporcional, ele foi mais significativo no Centro-Oeste, depois no Nordeste, no Sul e no Sudeste.

Em um intervalo de apenas sete anos surgiram, portanto, 51 novos cursos de formação de professores de Sociologia no Brasil, um aumento de 77\% em termos nacionais. E nesses novos cursos, houve uma queda na participação das instituiçóes universitárias, agora responsáveis por $75 \%$ dos cursos oferecidos, e uma queda menos significativa na proporçáo de cursos alocados em IES públicas (66\%), visto que os cursos privados criados nesse período concentraram-se, exclusivamente, nas regiōes Sul e Sudeste. Chama a atenção a criaçáo de cursos de formaçáo de professores de Sociologia que náo possuem a nomenclatura de licenciatura em Ciências Sociais: oito dos que surgiram nesse período denominam-se licenciaturas em Sociologia, além das licenciaturas em Ciências Humanas com habilitação em Sociologia e da Licenciatura em Sociologia como segundo ciclo do bacharelado em Humanidades, ou seja, 13 cursos - $(26 \%)$ dentre os novos criados - possuem uma nomenclatura diversa daquela mais recorrente.

\section{Análise do cenário de suas transformações}

Os dados apresentados apontam para um crescimento significativo no número de cursos de Ciências Sociais, o que segue a tendência mais ampla que encontramos no Ensino Superior brasileiro; contudo, acredito que há singularidades que devem ser consideradas. Apesar da heterogeneidade existente, esses cursos ainda se encontram prioritariamente junto a instituiçóes universitárias públicas, o que vai à contramão na expansão vivenciada no Brasil, 
marcada principalmente por uma oferta mais diversificada no Ensino Superior (NEVES, 2002).

Mostra-se inegável o fato de que a reintrodução da Sociologia no currículo escolar foi capaz de impactar o cenário das Ciências Sociais no Ensino Superior, fomentando a criação de novos cursos, em que pese o fato de que devemos considerar a confluência de outros fatores para compreendermos o que ocorreu, já que a volta da Sociologia à escola se deu no período de implantação do Programa de Apoio a Planos de Reestruturação e Expansão das Universidades Federais (REUNI) ${ }^{12}$, bem como de criação dos Institutos Federais, que passaram a atuar também na oferta de licenciaturas, não à toa, quatro dos novos cursos se vinculam a essas instituiçóes, embora se trate de uma inserçáo ainda problemática na estrutura da rede de Educação Profissional e Tecnológica (PANSARDI, 2013) ${ }^{13}$.

É válido rememorar que este cenário também possibilitou a criação de novos cursos de bacharelado, apesar de o crescimento não ter sido tão intenso. Cabe destacer que muitos dos novos cursos passaram a ofertar exclusivamente a habilitação da licenciatura; porém, em alguns casos, criaram-se inclusive bacharelados com um caráter mais disciplinar em Antropologia, Ciência Política e Sociologia ou, ainda, a partir de outros arranjos como Antropologia e Arqueologia, Ciência Política e Relaçóes Internacionais, Ciência Política e Sociologia, o que aponta para outras possibilidades de diálogos intelectuais.

A manutenção de uma predominância do setor público na oferta de cursos de formação de professores de Sociologia no Brasil pode ser compreendida, por um lado, por essa confluência de fatores com relação à expansão da rede federal de ensino no período em que a Sociologia volta à escola; por outro lado, pode-se aventar a hipótese de que haveria impasses postos com relação à legitimidade da Sociologia no currículo escolar, aprofundados pela ausência de professores com formação na área para lecioná-la, e pela presença normalmente reduzida a uma única aula semanal nas turmas de Ensino Médio, de tal modo que a busca por tais cursos não teria crescido de forma significativa

12 Esse peso do Reuni, como pode ser verificado ante ao exame dos dados trazidos, pode ser relativizado em algumas regiões do Brasil, tendo em vista, por exemplo, a relevância das Universidades Estaduais nesse processo na região nordeste.

13 Para uma melhor análise dessa política pública, ver: Léda e Mancebo, 2009 e Araújo e Pinheiro, 2010. 
a ponto de criar uma maior mobilização por parte do setor privado na oferta de tais licenciaturas.

Outra hipótese que pode ser levantada aqui é a relação entre a oferta de cursos por IES públicas e o processo de institucionalização da Sociologia nos currículos escolares, pois, ao que tudo indica, a presença delas parece ser fundamental nesse processo, o que não se restringe à oferta de vagas no âmbito da formação inicial, como também através da produção de conhecimento da área, e da formação continuada por meio da pós-graduação, tendo em vista que a maior parte dos programas de pós-graduação em Ciências Sociais concentram-se em IES públicas ${ }^{14}$.

Chama a atenção, nesse cenário, o advento da primeira linha de pesquisa voltada para a o Ensino de Sociologia, junto ao Programa de Pós-Graduação em Ciências Sociais da Universidade Estadual de Londrina em 2012, e do Mestrado Profissional em Ciências Sociais para o Ensino Médio em 2013. Deve-se, no entanto, ressaltar que a Educação ocupa um espaço diminuto na agenda de pesquisa dos Programas de Ciências Sociais/Sociologia no Brasil (LIMA; CORTES, 2013), e que mesmo as pesquisas no campo da Sociologia da Educação - desenvolvidas, portanto, por pesquisadores vinculados aos Departamentos de Ciências Sociais/Sociologia - voltam-se, prioritariamente, para o Ensino Superior (MARTINS; WEBER, 2010).

Há aqui uma diferença sutil que diferencia substancialmente o primeiro grupo, dos cursos criados até 2007, do segundo, que se refere à presença de programas de pós-graduação na área de Ciências Sociais. Dos cursos existentes no primeiro grupo, $54 \%$ contam com programas na área ${ }^{15}$, ao passo que apenas $12 \%$ possuem pós-graduação na área, em sua maioria apenas no nível de mestrado, ainda assim, recorrentemente, a criação da pós-graduação antecedeu o advento da licenciatura; todavia, normalmente, com um bacharelado

14 Há, atualmente, 22 programas de pós-graduação em Antropologia no Brasil, 14 em Ciência Política, 25 em Ciências Sociais, 19 em Sociologia, 3 em Sociologia Política, 2 em Sociologia e Antropologia, e um Mestrado Profissional em Ciências Sociais para o Ensino Médio. Existem, ainda, outros cursos junto a tais áreas de Avaliação da CAPES; porém, selecionei aqui apenas aqueles cujas denominações refletem um caráter mais evidentemente disciplinar.

15 Nesse caso, estou considerando o Mestrado Profissional em Planejamento e Políticas Públicas, bem como o Programa de Pós-Graduação em Políticas Públicas e Sociedade junto à Universidade Estadual do Ceará (UECE), visto que, embora não apresentem um caráter mais evidentemente disciplinar - no sentido de não serem programas de Sociologia ou Ciências Sociais -, encontram-se alocados nessa área de avaliação. 
que lhe é anterior, o que pode apontar para uma reafirmação do lugar periférico que a formaçáo docente ocupa historicamente nos cursos de Ciências Sociais (MORAES, 2003).

Pode-se interpretar esse cenário a partir de duas hipóteses: a primeira apontaria para a fragilidade em termos de articulação entre ensino de pesquisa, o que também pode ser compreendido a partir da incipiência desses cursos, os quais, estando ainda em processo de consolidação, demandariam mais tempo para solidificar suas bases de pesquisa; a segunda hipótese é que estaria posto em curso um processo de redirecionamento de esforços por parte das graduaçóes em Ciências Sociais/Sociologia, enfocando mais diretamente na questão do ensino, o que reflete as próprias demandas que emergem a partir da dinâmica da Educação Básica.

Esse redirecionamento dos cursos de Ciências Sociais para o ensino náo pode deixar de ser compreendido ante a conjuntura existente, aliás, esta é a hipótese que sustento neste artigo: as transformaçóes que ocorrem na Educação Básica afetam diretamente o Ensino Superior. Estou examinando um caso particular, ou seja, como a reintrodução da Sociologia afetou os cursos de Ciências Sociais; então, no meu entender o principal e mais imediato impacto foi a expansão das licenciaturas. Dessa forma, o redirecionamento que indico é impactado, também, pelo conjunto de políticas públicas educacionais que passam a incidir sobre tais cursos, o que inclui o financiamento para o desenvolvimento de atividades ligadas ao ensino.

Do mesmo modo, a emersão de cursos denominados de Sociologia indica uma maior afinidade entre a disciplina escolar e o curso superior, apontando para o fato de que tal curso, ao assumir essa nomenclatura, denota claramente que sua finalidade é formar professores para lecionar esta disciplina na escola, sem que, com isso, se perca de vista a articulaçáo com a Antropologia e a Ciência Política, pois essa é uma questáo extremamente cara que se coloca nas diretrizes de criação de tais cursos (BRASIL, 2001; OLIVEIRA, 2013a).

Observa-se que, tendencialmente, nas regiōes onde a Sociologia inicialmente foi introduzida - onde ocorreu uma atuação mais intensa das associaçóes profissionais na luta pela presença dessa ciência no currículo escolar, bem como uma aproximaçáo mais enfática entre Secretarias Estaduais de Educação e a academia (CARIDÁ, 2014) -, houve, também, uma presença mais 
significativa das IES privadas na oferta de cursos superiores na área, o que pode ser compreendido como um reflexo de uma maior legitimidade dessa disciplina no currículo escolar, que provocaria uma maior demanda pelas licenciaturas em Ciências Sociais/Sociologia.

Ao que me parece, mesmo diante de uma presença crescente do setor privado e das instituiçóes não universitárias, o que fica ainda mais evidente, se considerarmos os cursos ofertados na modalidade $\mathrm{EAD}$, é que o lugar das universidades públicas nesse processo ainda é central. Como o processo de legitimação da Sociologia no currículo escolar, a meu ver, ainda está em curso, ao menos se considerarmos o cenário nacional - tendo em vista que alguns impasses ainda precisam ser superados, por exemplo, com relação à quantidade de aulas semanais no currículo do Ensino Médio - acredito que a expansáo do número de cursos de formação de professores de Sociologia continuará nos próximos anos. No entanto, penso que a tendência é que essa outra fase da expansão seja protagonizada pelas instituiçóes não universitárias privadas, com destaque para os cursos na modalidade EAD. Essa hipótese pode ser aventada considerando tanto o movimento mais amplo do Ensino Superior brasileiro, quanto outros aspectos, como os limites do REUNI.

Caso esse prognóstico se concretize, de uma crescente expansão capitaneada pelas instituiçóes privadas, é relevante considerar as seguintes questóes. Assim, conforme explica Martins (2009, p. 28-29), nos últimos 40 anos, o ensino superior brasileiro se estruturou como

[...] um campo acadêmico complexo, heterogêneo, no qual as instituições passaram a ocupar posições dominantes e/ou dominadas em função dos critérios específicos que definem o prestígio e o reconhecimento dos estabelecimentos. Não seria de todo incorreto levantar a suposição de que houve, nas últimas décadas, um processo de hierarquização acadêmica no interior do campo do ensino superior brasileiro.

Dessa forma, algumas universidades públicas (federais e estaduais) e determinadas universidades privadas (geralmente as confessionais) se organizaram gradualmente, de modo a se aproximarem de um modelo acadêmico neo-humboldtiano. Essas instituições criaram estruturas acadêmicas que propiciaram a produção científica institucionalizada, desenvolveram cursos de pós-graduação stricto sensu, promoveram a profissionalização da carreira acadêmica, adotaram o regime de tempo integral para seus docentes, preservaram a liberdade acadêmica, associaram as atividades de ensino e pesquisa, implantaram programas de iniciação cientifica em parceria com agências de fomento nacionais. Em 2006, as universidades públicas federais e estaduais concentravam $70 \%$ dos docentes de tempo integral e 
64\% dos doutores no país (Scott, 2006; Sguissardi, 2005; Casper $E$ Humbolt, 1997; Charle E Verger, 1994).

Por sua vez, as instituições privadas de perfil empresarial estruturaram atividades que guardam certas afinidades acadêmicas com o modelo neo-napoleônico. De modo geral, essas instituições basicamente estão voltadas para uma estrita formação profissional e empregam professores horistas com pequeno volume de titulação acadêmica, que se dedicam em sua maior parte às atividades de ensino. Predomina em seu interior uma ausência de estruturas consolidadas de pesquisa e de pós-graduação stricto sensu. As instituições particulares com fins lucrativos concentram apenas 14\% dos docentes de tempo integral e 16\% dos doutores do país.

Creio que essa análise realizada por Martins (2009) é relevante para o cenário para o qual me volto neste artigo, pois, trata-se de compreender que a formaçáo de professores de Ciências Sociais/Sociologia está em um processo de deslocamento contínuo, no qual o "modelo acadêmico neo-humboldtiano" deixa tendencialmente de ser aquele que predominantemente forma tais licenciados, ainda que valha a pena enfatizar mais uma vez que esta é uma tendência observada; afinal, o curso pode ser alterado mediante alteraçóes significativas que venham a ocorrer na organização curricular da Educação Básica brasileira. No entanto, isso se aplica principalmente para a oferta de cursos de formação inicial. E não me refiro aqui à formação em nível de pós-graduação e à produçáo de conhecimento na área, uma vez que a maior parte dos cursos de pós-graduação concentra-se em universidades públicas.

Não sem menor relevância, devo mencionar que esse processo de expansão se deu concomitante à criação do Programa Institucional de Bolsas de Iniciação à Docência, havendo 73 subprojetos disciplinares na área de Ciências Sociais espalhados por todo o Brasil ${ }^{16}$, além de alguns interdisciplinares que abarcam as Ciências Sociais em associação com outras áreas. Tais projetos, em avaliações recentes (OLIVEIRA, LIMA, 2013; GONÇALVES, LIMA FILHO, 2014; SANTOS, 2014), demonstram um relevante papel no processo formativo, impactando positivamente a licenciatura junto aos cursos de Ciências Sociais.

Tal programa tem criado a possibilidade de constituição de uma maior aproximação entre os cursos de formação de professores e a escola, além do

16 Dados referentes ao ano de 2013. Ver Brasil, 2013. 
desenvolvimento de investigaçóes sobre a realidade do Ensino de Sociologia, o que é bastante relevante considerando o incipiente acúmulo de conhecimento nessa área.

Essas tendências apontam para uma superação em médio e em longo prazo de um de nossos principais dilemas: a ausência de professores com formação na área lecionando nas escolas, ainda que esse possa ser compreendido apenas como uma parte das questóes que se colocam para as Ciências Sociais na Educação Básica, tendo em vista que a formação continuada também é um desafio, bem como a solidificaçáo da temática do Ensino de Sociologia na agenda de pesquisa das Ciências Sociais e uma melhor articulação entre as três áreas das Ciências Sociais na Educação Básica. E isso parece um desafio ainda mais hercúleo com uma aula semanal, que é o cenário da maior parte das redes de ensino do país.

A expansão quantitativa de tais cursos vem sendo acompanhada também de uma revisão dos modelos de formação docente que vêm sendo adotados, e devem ser repensados ante as demandas emergentes.

Para mim, parece inconcebível que sejam formados professores de Sociologia hoje, em um momento em que a disciplina encontra-se presente no currículo escolar de todo o país e em que há distribuição de livros didáticos na área para as escolas públicas, do mesmo modo que formávamos docentes quando essa disciplina inexistia nas escolas.

Os cursos que surgiram após a reintrodução da Sociologia no currículo escolar parecem incorporar mais claramente as novas demandas que têm surgido, dando maior ênfase ao debate sobre as metodologias de ensino, o que também pode ser sentido em algum grau pelos demais cursos que passam a repensar seus modelos formativos, ainda que uma análise mais pormenorizada de todos os Projetos Pedagógicos de Curso não tenha sido realizada aqui ${ }^{17}$, o que torna inviável realizar generalizaçóes mais amplas nesse momento.

\section{Considerações finais}

Os dados apresentados visam elucidar qual o cenário que temos hoje no que se refere à formaçáo de professores de Sociologia no Brasil, marcado por

17 Em trabalho anterior analisei com maiores detalhes os cursos de formação de professores de Sociologia do Nordeste, considerando aqueles criados até o ano de 2013 (OLIVEIRA, 2014). 
uma rápida expansão alavancada pela reintrodução da Sociologia na Educação Básica. A partir do que foi apresentado, pode-se observar que as Licenciaturas em Ciências Sociais estáo alocadas principalmente nos cursos universitários públicos, apesar de uma crescente participaçáo de instituiçóes privadas e não universitárias, especialmente nas regióes Sul e Sudeste.

Há atualmente 117 licenciaturas presenciais que formam professores para lecionar Sociologia na Educação Básica no Brasil, 43\% delas criadas após a reintrodução da Sociologia no currículo escolar, no entanto, há que se considerar o rápido incremento dos cursos na modalidade $\mathrm{EAD}$, que subvertem o cenário que encontramos nos cursos presenciais, uma vez que se concentram majoritariamente em instituiçóes privadas, sendo ainda bastante tímida e pontual a presença de universidades públicas nesse segmento (OLIVEIRA, BRUM, 2014). Sua distribuição no território nacional é profundamente heterogênea, especialmente se considerarmos o caráter das IES, havendo regióes com apenas cursos ofertados por universidades públicas, outras por uma maior diversidade institucional.

Esse aumento quantitativo da oferta não pode escamotear a realidade que aponta para uma demanda ainda mais profunda em termos de formação de professores, pois ainda temos um cenário no qual predominam os professores com outras formaçóes lecionando Sociologia nas escolas, em muitos casos completando sua carga horária mínima semanal. Portanto, a expansão quantitativa dos cursos só será plenamente efetiva em suas finalidades se acompanhada de um conjunto de políticas públicas que garantam melhores condiçóes de trabalho docente, o que implica no caso da Sociologia também da existência de um número mínimo de carga horária semanal que viabilize a prática pedagógica do professor, tendo em vista que na maior parte do país há apenas uma aula semanal nos currículos escolares (SILVA, 2010).

Ademais há de se considerar que a oferta de vagas não implica em seu preenchimento total, bem como na conclusão do curso, ou ainda, pensando de uma forma ainda mais extrema, não há certezas sobre a atuaçáo posterior dos egressos dos cursos de licenciatura, que podem optar por seguir carreira acadêmica, ou ainda atuar em outras profissões. Um acompanhamento mais cuidadoso dos egressos do curso por parte das instituiçóes que ofertam tal 
formação seria um instrumento valioso para as pesquisas futuras, além de possibilitar que as instituiçóes formadoras tenham mais elementos para repensar seus modelos de graduação.

Outra questão que merecerá maior atenção dos pesquisadores nos próximos anos será a questáo da formação continuada, pois esta se mostra como algo relevante para os professores que estáo em sala de aula, sem embargo ainda não encontra o espaço necessário na agenda da pós-graduação em Ciências Sociais no Brasil, o que pode indicar a necessidade de se buscar outros caminhos, como a formulação de programas específicos de formação docente em nível de pós-graduaçóes stricto sensu profissionais ou acadêmicas, ou ainda cursos de extensão e de pós-graduação lato sensu.

A expansão quantitativa de tais cursos responde em parte às demandas existentes; porém, há que se fazer um exame mais minucioso sobre em que medida os modelos de formação docente que temos adotado de fato conseguem atender responder às questóes que se colocam em sala de aula, ou em outros termos, em que medida conseguimos formar professores de Sociologia de fato?

\section{Referências}

ARAÚJO, M. A. D.; PINHEIRO, H. D. Reforma gerencial do Estado e rebatimentos no sistema educacional: um exame do Reuni. Ensaio: aval. pol. públ. Educ., v. 18, n. 69, p. 647-668, 2010. BRASIL. Parecer CNE/CES no 492/2001, de 3 de abril de 2001. Diretrizes Curriculares Nacionais dos cursos de Filosofia, História, Geografia, Serviço Social, Comunicação Social, Ciências Sociais, Letras, Biblioteconomia, Arquivologia e Museologia. Diário Oficial da União, Brasília, DF, 9 de julho de 2001. Disponível em: <http://portal.mec.gov.br/cne/arquivos/pdf/CES0492.pdf>. Acesso em: 10 jul. 2015.

Parecer CNE/CBE no 38/2006, de 7 de julho de 2006. Inclusão obrigatória das disciplinas de Filosofia e Sociologia no currículo do Ensino Médio. Diário Oficial da Uniáo, Brasília, DF, 14 de agosto de 2006. Disponível em: <http://professor.cee.ce.gov.br/index.php/espacodaaula/ educacao-basica/file/1666-parecer-cne-ceb-n-38-2006-aprovado-em-7-de-julho-de-2006>. Acesso em: 10 jul. 2015.

Lei no 11.648, de 2 de junho de 2008. Altera o art. 36 da Lei no 9.394, de 20 de dezembro de 1996, que estabelece as diretrizes e bases da educaçáo nacional, para incluir a Filosofia e a 
Sociologia como disciplinas obrigatórias nos currículos do ensino médio. Diário Oficial da União, Brasília, DF, 3 de junho de 2008. Disponível em: Acesso em : 10 jul. 2015.

Ministério da Educação. Capes. Formação de Professores da Educação Básica. 2013. Disponível em: <http://www.capes.gov.br/educacao-basica>. Acesso em: 10 jul. 2015.

Sistema e-MEC. 2015. Disponível em: <http://emec.mec.gov.br/>. Acesso em: 10 jul. 2015.

CARIDÁ, A. C. B. B. Sociologia no Ensino Médio: diretrizes curriculares e trabalho docente. 2014. 145 f. Dissertação (Mestrado em Sociologia e Política) - Centro de Filosofia e Ciências Humanas, Universidade Federal de Santa Catarina, Florianópolis, 2014. Disponível em: <https:// repositorio.ufsc.br/bitstream/handle/123456789/123334/326272.pdf?sequence=1\&isAllowed $=y>$. Acesso em: 10 jul. 2015.

GONÇALVES, D. N.; LIMA FILHO, I. P. Aprendendo pela Pesquisa e pelo Ensino: o PIBID no processo formativo das licenciaturas em Ciências Sociais. Revista Brasileira de Sociologia, v. 2, n. 3, p. 81-100, 2014.

HANDFAS, A.; MAÇAIRA, J. P. O estado da arte da produção científica sobre o ensino de sociologia na educação básica. BIB - Revista Brasileira de Informação Bibliográfica em Ciências Sociais, São Paulo, v. 2, n. 74, p. 45-61, 2014.

LÉDA, D. B.; MANCEBO, D. Reuni: heteronomia, precarização da universidade e do trabalho docente. Educaçáo \& Realidade, v. 34, n. 9, p. 49-64, jan./abr. 2009.

LIEDKE FILHO, E. D. Sociologia Brasileira: tendências institucionais e epistemológico-teóricas contemporâneas. Sociologias, n. 9, p. 216-245. 2003.

LIMA, J. C.; CORTES, S. M. V. A sociologia no Brasil e a interdisciplinaridade nas ciências sociais. Civitas, Porto Alegre, v. 13, n. 2, p. 416-435, 2013.

MAGGIE, Y. Por que gostamos tanto do curso de Ciências Sociais? In: GROSSI, M. P.; TASSINARI, A.; RIAL, C. (Org.). Ensino de Antropologia no Brasil: formação, práticas disciplinares e alémfronteiras. Blumenau: Nova Letra, 2006. p. 259-280.

MARTINS, C. B. A Reforma Universitária de 1968 e a abertura para o ensino superior privado do Brasil. Educaçáo \& Sociedade, v. 30, n. 106, p. 15-35, 2009.

.; WEBER, S. Sociologia da Educação: democratização e cidadania. In:

MARTINS, H. H. T. de S. Horizontes das Ciências Sociais: Sociologia. São Paulo: ANPOCS, 2010. p. 131-201. 
MEUCCI, S. Institucionalizaçáo da sociologia no Brasil: primeiros manuais e cursos. São Paulo: Hucitec; Fapesp, 2011.

MICELI, S. Condicionantes do desenvolvimento das ciências sociais. In: . (Org.). História das Ciências Sociais no Brasil. São Paulo: Vértice; IDESP; FINEP, 1989. v. 1. p. 72-110.

MORAES, A. C. Licenciatura em ciências sociais e ensino de sociologia: entre o balanço e o relato. Tempo Social, São Paulo, v. 15, n. 1, p. 5-20, 2003.

NEVES, C. E. B. Estudos Sociológicos sobre Educação no Brasil. In: MICELI, S. (Org.). O que ler na ciência social brasileira 1970-2002. São Paulo; Brasília: Editora Sumaré; CAPES, 2002. v. IV. p. 351-437.

.; RAIZER, L.; FACHINETTO, R. F. Acesso, expansão e equidade na educação superior: novos desafios para a política educacional brasileira. Sociologias, v. 9, n. 17, p. 124-157, 2007.

OLIVEIRA, A. Formação de Professores de Ciências Sociais ante às Políticas Educacionais. Crítica e Sociedade: revista de cultura política, Uberlândia, v. 3, n. 2, p. 132-152, 2013 a.

Revisitando a história do ensino de Sociologia na Educação Básica. Acta Scientiarum. Education, Maringá, v. 35, n. 2, p. 179-189, july/dec. 2013b.

A Formação Inicial de Professores de Sociologia no Nordeste: alguns breves apontamentos. Pesquiseduca, v. 6, n. 12, p. 285-299, 2014. .; BRUM, C. Ciências Sociais a Distância: apontamentos sobre os desafios da formação de professores no Brasil. O Público e o Privado (UECE), n. 24, p. 26-39, 2014.

.; LIMA, V. S. Formação de Professores em Ciências Sociais: Desafios e possibilidades a partir do Estágio e do PIBID. Inter-Legere, n. 13, p. 140-162, jul./dez. 2013. Disponível em: <http://www.cchla.ufrn.br/interlegere/13/pdf/es09.pdf>. Acesso em: 10 jul. 2015.

PANSARDI, M. V. Um estranho no ninho: a formação de professores em sociologia nos Institutos Federais. Inter-legere, n. 13, p. 245-249, jul./dez. 2013. Disponível em: <http://www.cchla.ufrn. br/interlegere/13/pdf/es11.pdf>. Acesso em: 10 jul. 2015.

SANTOS, M. B. O PIBID na área de Ciências Sociais: condiçóes epistemológicas e perspectivas sociológicas. Revista Brasileira de Sociologia, v. 2, n. 3, p. 55-79, 2014.

SILVA, I. L. F. O ensino das ciências sociais/Sociologia no Brasil: histórico e perspectivas. In: MORAES, A. C. (Org.). Coleçáo explorando o ensino de Sociologia. Brasília: MEC, 2010. p. 23-31. 
Recebido em: 10.07.2015

Aceito em: 20.10.2015

\section{Scenarios, trends and challenges in Social Sciences teacher training in Brazil}

\section{Abstract}

The law $n^{\circ} 11.684 / 2008$ that reintroduced the Sociology in Basic Education brought new challenges not only for schools but also for Higher Education Institutions (HEls), which has the most immediate effect the increase in the number of teacher training courses in Social Sciencel Sociology. This article seeks to present the current situation of teacher training courses in Brazil in quantitative terms, indicating their distribution by country as well as the expansion of such courses held with the reintroduction of Sociology in high school. Later, we seek to carry out an analysis of the data presented, indicating the trends that can be perceived, and also what challenges lay ahead for the training of teachers of Social Sciences / Sociology in this new scenario.

Keywords: Teaching Sociology. Teachers training in Social Sciences. Higher education. Sociology of Education. 